\title{
Glucose-Induced Alkalosis in Fasting Subjects
}

\author{
RELATIONSHIP TO RENAL BICARBONATE REABSORPTION \\ DURING FASTING AND REFEEDING
}

\author{
Bobby J. Stinebaugh and Francis X. Schloeder \\ From the Renal Section, Department of Internal Medicine, \\ Gorgas Hospital, Ancon, Canal Zone
}

A B S T R A C T This study documents the development of alkalosis in patients returning to caloric intake after a period of starvation and investigates the mechanisms responsible for this metabolic alteration. We studied the acid-base status, bicarbonate reabsorption, acid excretion, and sodium metabolism during fasting and glucose refeeding in 19 patients receiving sodium supplements.

Metabolic alkalosis developed promptly in all of the subjects who terminated an 18 day fast with $300 \mathrm{~g}$ of glucose daily for 4 days. Tubular maximum reabsorptive capacity for bicarbonate and renal bicarbonate threshold determinations were performed at varying intervals in six and seven subjects, respectively, who had fasted for 3-18 days. The results demonstrated that bicarbonate reabsorptive capacity was normal or low during early fasting, markedly elevated during the 2 nd wk; and moderately elevated during the 3rd wk of fasting. Glucose administration at all stages of fasting caused a further increase in bicarbonate threshold.

Sodium balance during fasting with sodium supplements was found to follow a triphasic pattern, with the occurrence of a natriuresis during the $1 \mathrm{st}$ wk followed by a period of sodium retention after which neutral daily sodium balance was reestablished. Correlation of bicarbonate reabsorption with sodium homeostasis indicated a slight decrease in renal bicarbonate threshold during the natriuretic phase, a marked increase in bicarbonate reabsorption during the period of sodium retention, and a continued moderate elevation of threshold after sodium balance was reestablished. This relationship was interpreted to indicate that changes in bicarbo-

Dr. Schloeder's present address is Renal Section, KelseySeybold Clinic, Houston, Tex.

Requests for reprints should be addressed to: Box 0, Balboa Heights, Canal Zone.

Received for publication 22 July 1971 and in revised form 29 December 1971. nate reabsorption during fasting and refeeding may be secondary to alterations in the renal reabsorption of sodium.

\section{INTRODUCTION}

That fasting patients may develop systemic alkalosis when they resume food intake has been reported $(1,2)$ but not investigated. We studied this metabolic alteration in normal human volunteers and have established that this occurs regularly in the postfasting state. In order to elucidate the mechanism of this phenomenon, we measured acid excretion, bicarbonate reabsorption, and sodium metabolism during fasting and refeeding with glucose in individuals given various sodium supplements. Results indicate that the alkalosis of refeeding is due to an increased renal tubular bicarbonate reabsorptive capacity resulting directly from fasting, which is further accentuated by carbohydrate refeeding. These findings appear to be related to changes in renal tubular handling of sodium both during fasting and upon refeeding.

\section{METHODS}

19 moderately obese but otherwise healthy female volunteers were admitted to the Clinical Study Unit of Gorgas Hospital to fast for purposes of weight reduction. Their age ranged from 18 to $45 \mathrm{yr}$ (average 32.3) and weight from 64.1 to $90.8 \mathrm{~kg}$ (average 76.6). Initial evaluation studies, including history and physical examination, complete blood count, urinalysis, chest X-ray, electrocardiogram, serum electrolytes and proteins, endogenous creatinine clearance, colony count, protein excretion, and glucose tolerance test were within normal limits. These studies were conducted over a 4 day period while the volunteers consumed a diet of $1800 \mathrm{cal}$ containing $40 \mathrm{mEq}$ of potassium and either 102 or $160 \mathrm{mEq}$ of $\mathrm{NaCl}$ daily. All subjects had normal bicarbonate thresholds before fasting as their serum bicarbonate concentrations were less than $28 \mathrm{mmoles} / \mathrm{liter}$ and all had 
random urine specimens with $\mathrm{pH}$ values greater than 6.10 . Sodium excretion was within $20 \mathrm{mEq}$ of intake on the 1st day of fasting in all subjects. Patients remained ambulatory in the air conditioned unit for the duration of the study. During fasting and refeeding all subjects received $50 \mathrm{mg}$ of thiamin and $60 \mathrm{mEq}$ of $\mathrm{KCl} /$ day, and distilled water ad lib. in addition to the sodium supplements. Electrolytes ${ }^{1}$ were administered in small doses over a 14-18 $\mathrm{hr}$ period under direct observation of the nursing staff. Nausea was experienced but vomiting did not occur. Patients were weighed daily on a metabolic balance after emptying the bladder, before any intake, and in the same state of attire.

All urine voided during the observation period was collected under refrigeration at $4^{\circ} \mathrm{C}$ in $24-\mathrm{hr}$ specimens in vessels containing thymol, phenyl mercuric nitrate, and mineral oil. Completeness of collections was verified by creatinine content. Venous blood was collected daily without stasis and before any intake or activity. Determinations of $\mathrm{pH}$, $\mathrm{P}_{\mathrm{CO}_{2}}$, and intratable acidity (TA) ${ }^{2}$ were made immediately, and portions of serum and urine were frozen for later determinations of other parameters.

15 subjects received $\mathrm{NaCl} 102 \mathrm{mEq}$ /day both equilibration and fasting, four received $\mathrm{NaCl} 160 \mathrm{mEq} /$ day during equilibration but during fasting received this amount of $\mathrm{NaHCO}_{3}$. This regime was terminated in five subjects after the 18th21st fasting day by a refeeding study during which they received $1200 \mathrm{cal} /$ day of glucose while continuing the ingestion of electrolytes. In six subjects, fasting was terminated on day $3,5,7,9,11$, or 15 by the determination of tubular maximum reabsorption of bicarbonate. In another seven subjects the effect of glucose administration on renal bicarbonate threshold was determined on day 4,7 , $9,11,13,15$, or 19 . The data from seven subjects who had fasted for at least 18 days were utilized to compose a sodium balance study, five of whom went on to the refeeding portion.

Tubular maximum reabsorption of bicarbonate (Tm$\mathrm{HCO}_{s}$ ). Measurement of $\mathrm{TmHCO}_{3}$ was performed by the constant infusion of a solution containing $1.26 \mathrm{~g} / 100 \mathrm{ml}$ $\mathrm{NaHCO}_{3}$ at a rate calculated to increase serum bicarbonate by 4 mmoles/liter per $\mathrm{hr}$ until urine $\mathrm{pH}$ exceeded 6.10 , at which time infusion rate was increased by $50 \%$. Urine was collected in consecutive $10-20$ min specimens from a urethral catheter draining into a graduated cylinder containing mineral oil. Venous blood samples were obtained anaerobically and without the use of tourniquets at the midpoint of each urine collection. Samples of both urine and blood were analyzed immediately for $\mathrm{pH}$ and $\mathrm{P}_{\mathrm{CO}_{2}}$. Glomerular filtration rate was estimated by the clearance of fresh iothalamate${ }^{125}$ I (Glofil; Abbot Laboratories, North Chicago, Ill.) (3).

The serum bicarbonate concentration was calculated from the Henderson-Hasselbach equation using values of $\mathrm{pK}^{\prime}$ and $\mathrm{S}$ of 6.10 and 0.0306 , respectively. Value of $\mathrm{pK}^{\prime}$ was calculated for each urine sample using the formula: $\mathrm{pK}^{\prime}=6.33$ $-0.5 \sqrt{\mathrm{Na}+\mathrm{K}(4)}$.

Tubular bicarbonate threshold $\left(T-\mathrm{HCO}_{\mathrm{s}}\right)$. The effect of fasting and glucose administration on $\mathrm{T}-\mathrm{HCO}_{3}$ was deter-

${ }^{1} \mathrm{NaCl}$ and $\mathrm{NaHCO}_{3}$ were administered as 1,000 or 600 $\mathrm{mg}$ tablets which by analysis did not vary by more than $0.3 \mathrm{mEq}$. $\mathrm{KCl}$ was administered as $15 \mathrm{~g} / 100 \mathrm{ml}$ solution by $10 \mathrm{ml}$ graduated cylinder to within $0.1 \mathrm{ml}$.

${ }^{2}$ Abbreviations used in this paper: GFR, glomerular filtration rate; TA, titratable acidity; $\mathrm{T}-\mathrm{HCO}_{3}$, tubular bicarbonate threshold; $\mathrm{TmHCO}_{3}$, tubular maximum reabsorption of bicarbonate.
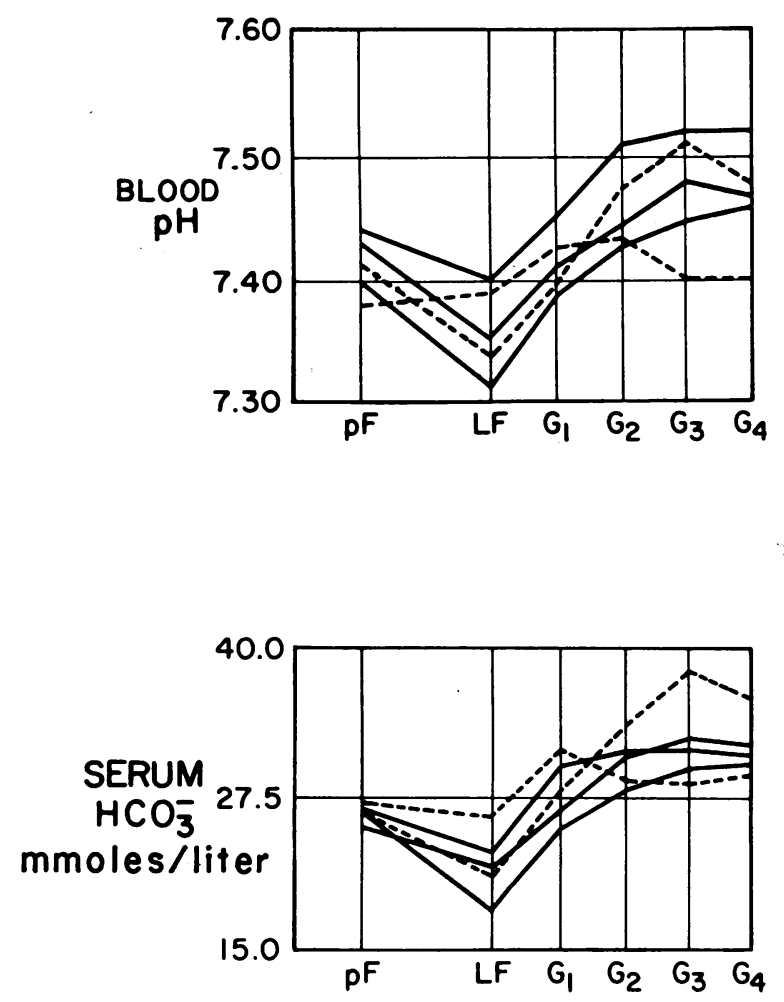

FiguRE 1 Blood $\mathrm{pH}$ and bicarbonate concentration in the five subjects of the refeeding study before fasting $(\mathrm{pF})$, after 18-21 days of fasting (LF) and after each day of refeeding with glucose $\left(\mathrm{G}_{1}-\mathrm{G}_{4}\right)$. Upon return to caloric intake there was a rapid rise to alkalotic levels in all, sometimes exceeding prefast values by the 2 nd refeeding day. Serum bicarbonate concentration in all remained significantly higher than their prefast concentrations throughout the refeeding period $(P<0.01)$. Black represents subjects receiving $\mathrm{NaCl}$; interrupted, the subjects receiving $\mathrm{NaHCO}_{3}$.

mined by the infusion of a solution containing $1.26 \mathrm{~g} / 100$ $\mathrm{ml} \mathrm{NaHCO}_{3}$ at a rate calculated to increase the serum bicarbonate by 4 mmoles/liter per $\mathrm{hr}$ while urine from an indwelling catheter draining into a cylinder containing mineral oil was monitored for $\mathrm{pH}$ and $\mathrm{P}_{\mathrm{CO}_{2}}$ at $10-15-\mathrm{min}$ intervals. When the urine $\mathrm{pH}$ reached $6.10{ }^{3}$ the infusion was stopped and $25 \mathrm{~g}$ of isotonic glucose were given orally over a $30 \mathrm{~min}$ period. After glucosuria ceased, the bicarbonate infusion was resumed. Urine $\mathrm{pH}$, which invariably decreased in the interim, was monitored until it again reached 6.10 . Venous blood was drawn at the midpoint of each urine collection period and at the time urine $\mathrm{pH}$ reached 6.10 Threshold was estimated as the mean of the values of serum bicarbonate concentration at the time urine $\mathrm{pH}$ reached 6.10 and the immediate previous observation.

Balance calculations. Calculations of the balances of sodium, potassium, and chloride were limited to comparison

${ }^{3}$ We have used the $\mathrm{pK}^{\prime}$ of $\mathrm{HCO}_{3}$ as the indicator of the renal tubular threshold for bicarbonate. Other authors have used 6.3-6.8 (5). Urine $\mathrm{pH}$ accurately reflected directional changes in urine bicarbonate concentration in these studies as urine $\mathrm{P}_{\mathrm{CO}_{2}}$ consistently varied directly with urine $\mathrm{pH}$. 


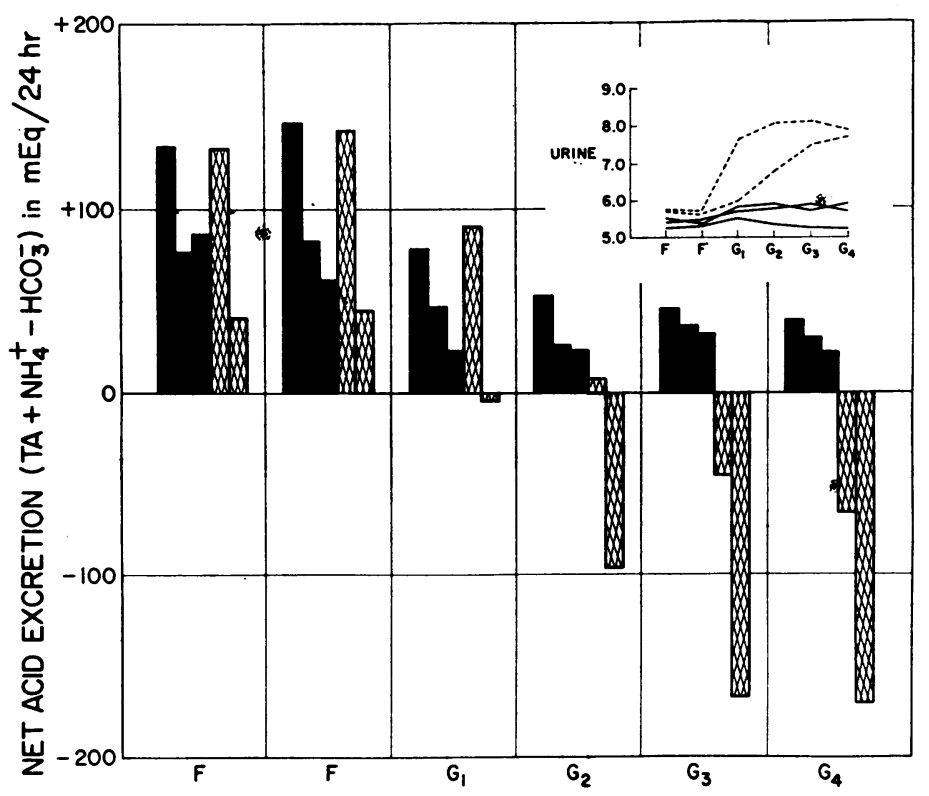

Figure 2 Net acid excretion on the last 2 fasting days ( $F$ ) and on each day of glucose administration $\left(G_{1}-G_{4}\right)$ of the five subjects of the refeeding study; negative values indicate net alkali excretion. A prompt decline of acid excretion occurred on the 1st day of glucose administration in all subjects. Thereafter, those receiving $\mathrm{NaCl}$ (black) continued to excrete $25-46 \mathrm{mEq}$ /day of net acid, while those receiving $\mathrm{NaHCO}_{3}$ (crosshatched) excreted varying amounts of the ingested bicarbonate. The insert shows urinary $\mathrm{pH}$ over this period, demonstrating that an acid urine continued throughout refeeding in those receiving $\mathrm{NaCl}$ (black lines). The urine of one subject on $\mathrm{NaHCO}_{3}$ (broken lines) remained acid on the 1st and 2nd day of refeeding, after which a portion of the ingested bicarbonate was excreted. The urine $\mathrm{pH}$ of the other subject on $\mathrm{NaHCO}_{3}$ (who had the least degree of systemic alkalosis during refeeding) rose to 7.34 on the 1st day and to 7.9-8.1 thereafter, with excretion of large quantities of net alkali.

of measured intake with measured urinary excretion on a 24-hr basis. This method was felt to be reasonably accurate: stools were rare and previous studies have demonstrated that fecal sodium losses are negligible in fasting subjects receiving sodium supplements of similar magnitude (6); skin chloride losses during fasting are less than $2 \mathrm{mEq} /$ day (7). Total blood drawn during the balance studies averaged 250 $\mathrm{ml}$ per patient and was not included in the calculations.

Analytical methods. Sodium and potassium were determined by Instrumentation Laboratories Model IL-143 flame photometer ; ${ }^{4}$ chloride by Buchler-Cotlove chloridometer ; blood $\mathrm{pH}$ and $\mathrm{P}_{\mathrm{CO}_{2}}$ by Instrumentation Laboratory Model IL-113 blood gas analyzer ; ${ }^{*}$ urine $\mathrm{pH}$ and TA by Radiometer Model TTT1c pH Meter and automatic titrator; ${ }^{\circ}$ urine ammonium by the microdiffusion method of Conway (8) ; glomerular filtration rate was estimated by the clearance of iothalamate- $I^{125}$ (Glofil). Statistical analyses were by standard $t$ tests or paired $t$ tests, as described by Snedecor (9).

- Instrumentation Laboratory, Inc., Lexington, Mass.

s Buchler Instruments, Inc., Fort Lee, N. J.

- Radiometer Co., Copenhagen.

\section{RESULTS}

Refeeding study. Refeeding was accomplished in five subjects (three on $\mathrm{NaCl}$ and two on $\mathrm{NaCHO}_{3}$ ) by the administration of $300 \mathrm{~g} /$ day of glucose $(20 \mathrm{~g} / \mathrm{hr}$ over a $15 \mathrm{hr}$ period) for 4 days, while ingestion of electrolytes continued unchanged. All promptly developed metabolic alkalosis (Fig. 1). The mean serum bicarbonate concentration at the end of fasting for these five patients was $21.7 \pm 1.3$ (mean \pm SEM) mmoles/ liter. After each of the 4 days of refeeding, values were $27.6 \pm 1.1, \quad 30.2 \pm 0.9, \quad 31.7 \pm 1.5$, and $31.3 \pm 1.0$ mmoles/liter. The greatest increment in bicarbonate concentration occurred on the 1 st day and averaged $5.9 \pm 0.6 \mathrm{mmoles} / \mathrm{liter}$. Individual highest concentrations during the refeeding period ranged from 30.2 to 37.4 mmoles/liter (mean 32.1 \pm 1.4 ). This maximum level was significantly higher than the value of $25.7 \pm 0.4$ mmoles/liter before fasting (mean increase $6.4 \pm 1.5$; 


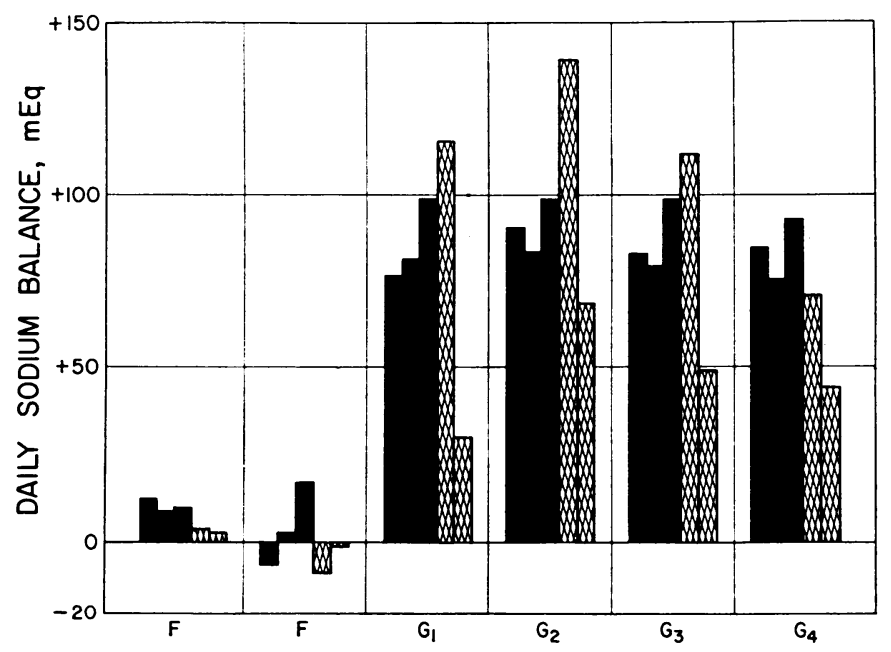

Figure 3 Daily sodium balance in five subjects on the last 2 fasting days $(F)$ and during glucose administration $\left(G_{1}-G_{4}\right)$. In neutral daily balance at the beginning of refeeding, all retained large amounts of the ingested sodium from the 1st day of refeeding with glucose, and no clear reduction of this retention was apparent over the 4 days of observation. Subjects on $\mathrm{NaCl}$ are in black, those on $\mathrm{NaHCO}_{3}$ are crosshatched.

$P<0.01)$. At the end of refeeding, serum bicarbonate concentration varied from 29.2 to $35.2 \mathrm{mmoles} / \mathrm{liter}$, individual increments over prefast levels of 2.4 to 9.6 mmoles/liter (mean 5.6 $\pm 1.2 ; P<0.01$ ).

Fig. 2 illustrates net acid excretion $\left(\mathrm{TA}+\mathrm{NH}_{4}{ }^{+}\right.$ $\left.-\mathrm{HCO}_{3}{ }^{-}\right)$on the last 2 days of fasting and during refeeding. There was a prompt decline in all subjects on the 1st day of glucose ingestion. Subsequently, those receiving $\mathrm{NaCl}$ continued to excrete $24-46 \mathrm{mEq} /$ day of net acid, while those given $\mathrm{NaHCO}_{3}$ declined to negative values for net acid, as bicarbonate excretion increased. The antinatriuretic effect of glucose was pronounced : patients given $\mathrm{NaCl}$ retained $77-99 \%$ of the ingested load each day and accumulated positive sodium balances of 322 and $392 \mathrm{mEq}$, while those receiving $\mathrm{NaHCO}_{3}$ retained $51-87 \%$ of the ingested dose (Fig. 3 ). All subjects gained weight and developed mild edema.

Effect of fasting on bicarbonate reabsorption. Initially all subjects had $\mathrm{T}-\mathrm{HCO}_{3}$ values of less than 28 mmoles/liter as evidenced by their prefast serum bicarbonate concentrations and random urine $\mathrm{pH}$ values of greater than 6.10. During early fasting the $\mathrm{T}-\mathrm{HCO}_{3}$ was either normal or slightly depressed, but by the 7 th day of fasting it was greater than the prefast value in all 10 of the studies $(P<0.001)$. Similarly the $\mathrm{TmHCO}_{3}$ was elevated in all six of the studies in which this value was determined after the 7 th day of fasting. A summary of all the data on bicarbonate reabsorption is presented in Table I. Typical protocols are shown in Tables II and III.
Sodium balance study. Daily sodium balance in two typical studies is depicted in Fig. 4. With the onset of fasting a natriuresis (urinary sodium excretion greater

TABLE I

Bicarbonate Threshold $\left(\mathrm{T}-\mathrm{HCO}_{3}\right)$ and Tm Values during Fasting and after Glucose Administration

\begin{tabular}{|c|c|c|c|c|c|}
\hline Day & $\mathrm{T}-\mathrm{HCO}_{3}$ & $\mathrm{TmHCO}_{3}$ & $\begin{array}{c}\mathrm{T}-\mathrm{HCO}_{3} \\
\text { after } \\
\text { glucose }\end{array}$ & $\begin{array}{c}\text { Daily } \\
\text { Na }+ \\
\text { balance }\end{array}$ & $\begin{array}{l}\text { Cumulative } \\
\mathrm{Na}+\text { balance }\end{array}$ \\
\hline & $\begin{array}{c}\text { mmoles/ } \\
\text { liter }\end{array}$ & $\begin{array}{c}\text { mmoles/ } \\
100 \mathrm{ml} \\
\text { GFR }\end{array}$ & $\begin{array}{c}\text { mmoles/ } \\
\text { liter }\end{array}$ & $m E q$ & $m E q$ \\
\hline 3 & 25.6 & 2.73 & & -24 & $-42(-57)$ \\
\hline 4 & 22.1 & & 27.1 & -24 & $-116(-136)$ \\
\hline 5 & 23.1 & 2.57 & & -29 & $-132(-157)$ \\
\hline 7 & 28.5 & 3.17 & & +48 & $-27(-62)$ \\
\hline 7 & 33.8 & & 35.3 & +65 & $-1(-36)$ \\
\hline 9 & 39.8 & 4.35 & & +46 & $+57(+22)$ \\
\hline 9 & 37.5 & & 37.9 & +29 & \\
\hline 11 & 34.3 & 4.00 & & +80 & $+129(+74)$ \\
\hline 11 & 33.2 & & 36.8 & +83 & \\
\hline 13 & 31.3 & & 33.9 & +25 & \\
\hline 15 & 31.7 & 3.42 & & -4 & $+242(+165)$ \\
\hline 15 & 31.8 & & 34.0 & +53 & $+173(+98)$ \\
\hline 19 & 32.0 & & 36.5 & +9 & $+154(+59)$ \\
\hline
\end{tabular}

Daily and cumulative sodium balance data up until day before bicarbonate study are included. Figures in parentheses represent cumulative sodium balance corrected for assumed extrarenal losses of $5 \mathrm{mEq} /$ day.

Glucose-Induced Alkalosis in Fasting Subjects

1329 
TABLE II

Representative Determination of $\mathrm{TmHCO}_{3}$ on 9 th Fasting Day*

\begin{tabular}{|c|c|c|c|c|c|c|c|c|c|}
\hline \multirow[b]{2}{*}{ Min } & \multicolumn{3}{|c|}{ Serum } & \multicolumn{3}{|c|}{ Urine } & \multicolumn{3}{|c|}{ Bicarbonate } \\
\hline & $\mathrm{pH}$ & $\mathrm{PCO}_{2}$ & $\mathrm{HCO}_{3}$ & $\mathrm{~V}$ & $\mathrm{pH}$ & GFR & Filtered & Excreted & Reabsorbed \\
\hline & & $m m \mathrm{Hg}$ & $\begin{array}{l}\text { mmoles/ } \\
\text { liter }\end{array}$ & $m l / \min$ & & $\begin{array}{ll}\mathrm{ml} / \mathrm{min} / \\
1.73 \mathrm{~m}^{2}\end{array}$ & $\mu m o l$ & $s / \min$ & $\begin{array}{l}\text { mmoles/ } \\
100 \mathrm{ml} G F\end{array}$ \\
\hline 0 & 7.26 & 33.7 & 14.3 & & 5.20 & & & & \\
\hline $\begin{array}{r}1 \\
3 \\
50\end{array}$ & \multicolumn{9}{|c|}{$\begin{array}{l}\text { Prime Glofil, } 34 \mu \mathrm{Ci} \\
\text { Start Glofil infusion, } 0.25 \mu \mathrm{Ci} / \mathrm{min} \\
\text { Start } \mathrm{NaHCO}_{3}, 1.26 \mathrm{~g} / 100 \mathrm{ml}, 11.3 \mathrm{ml} / \mathrm{min}\end{array}$} \\
\hline 320 & & & & & 5.75 & & & & \\
\hline 335 & & & & & 5.95 & & & & \\
\hline 350 & 7.59 & 39.9 & 37.5 & & 6.15 & & & & \\
\hline 355 & \multicolumn{9}{|c|}{ Increase $\mathrm{NaHCO}_{3}, 1.26 \mathrm{~g} / 100 \mathrm{ml}$ to $18.2 \mathrm{ml} / \mathrm{min}$} \\
\hline $359-379$ & 7.60 & 40.4 & 38.9 & 6.6 & 6.40 & 111.5 & 4.34 & 0.02 & 3.87 \\
\hline 379-399 & 7.63 & 41.8 & 43.0 & 8.1 & 7.30 & 137.6 & 5.92 & 0.19 & 4.16 \\
\hline $399-413$ & 7.64 & 42.6 & 44.7 & 8.8 & 7.46 & 118.4 & 5.29 & 0.41 & 4.12 \\
\hline $413-423$ & 7.65 & 42.0 & 45.4 & 10.2 & 7.58 & 127.9 & 5.81 & 0.59 & 4.08 \\
\hline $423-433$ & 7.66 & 42.2 & 46.8 & 10.1 & 7.62 & 130.8 & 6.12 & 0.68 & 4.16 \\
\hline $433-443$ & 7.66 & 42.8 & 47.5 & 12.2 & 7.58 & 133.1 & 6.32 & 0.61 & 4.29 \\
\hline $443-453$ & 7.67 & 42.8 & 48.8 & 11.7 & 7.61 & 131.3 & 6.41 & 0.68 & 4.36 \\
\hline $453-463$ & 7.67 & 43.0 & 49.0 & 12.8 & 7.67 & 114.9 & 5.63 & 0.63 & 4.35 \\
\hline $463-473$ & 7.68 & 42.8 & 50.1 & 13.1 & 7.68 & 122.5 & 6.14 & 0.80 & 4.36 \\
\hline $473-483$ & 7.68 & 43.4 & 50.8 & 13.6 & 7.78 & 127.8 & 6.49 & 0.95 & 4.34 \\
\hline $483-493$ & 7.69 & 43.2 & 51.6 & 14.4 & 7.82 & 139.8 & 7.21 & 1.12 & 4.36 \\
\hline
\end{tabular}

* GFR estimated by clearance of Glofil.

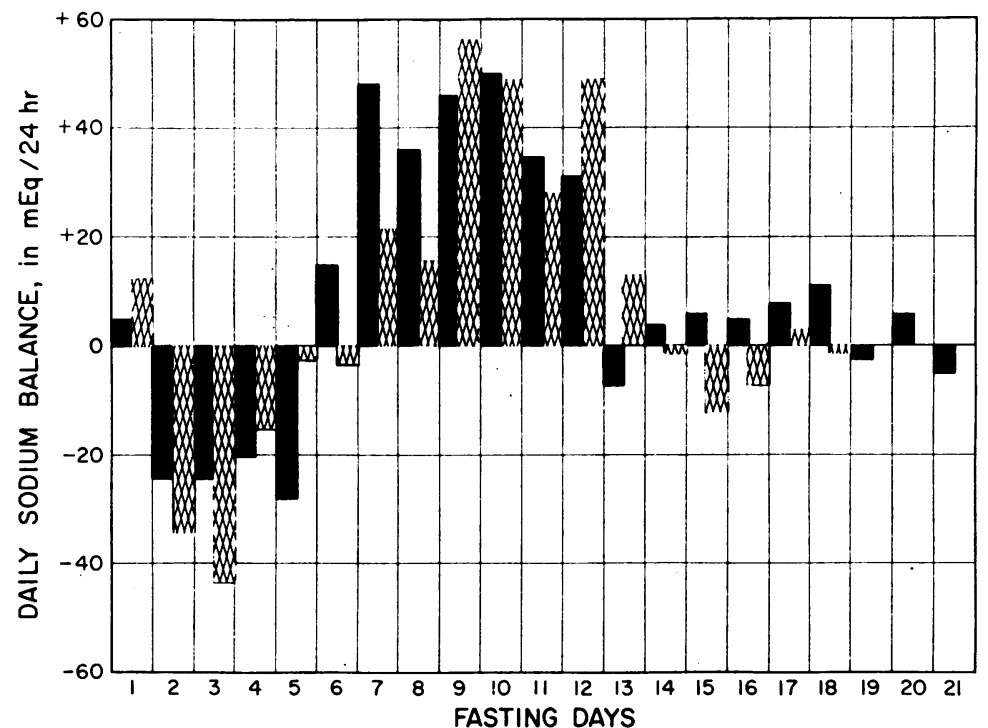

FIGURE 4 Daily sodium balance during 21 and 18 days of fasting in two representative subjects receiving either $\mathrm{NaCl}$ ( $102 \mathrm{mEq} /$ day; black) or $\mathrm{NaHCO}_{3}(160 \mathrm{mEq} /$ day ; crosshatched $)$. The "natriuresis of fasting" occurred over the first 6 days followed by a period of sodium retention and then resumption of neutral daily balance. The quantity of sodium retained from days 7-12 was greater than the total excreted over the first 6 days. No difference in this triphasic pattern is apparent between the two sodium salts or the different quantities received. 
TABLE III

Representative Determination of Bicarbonate Threshold before and Immediately after Glucose Administration during Fasting (Day 19)

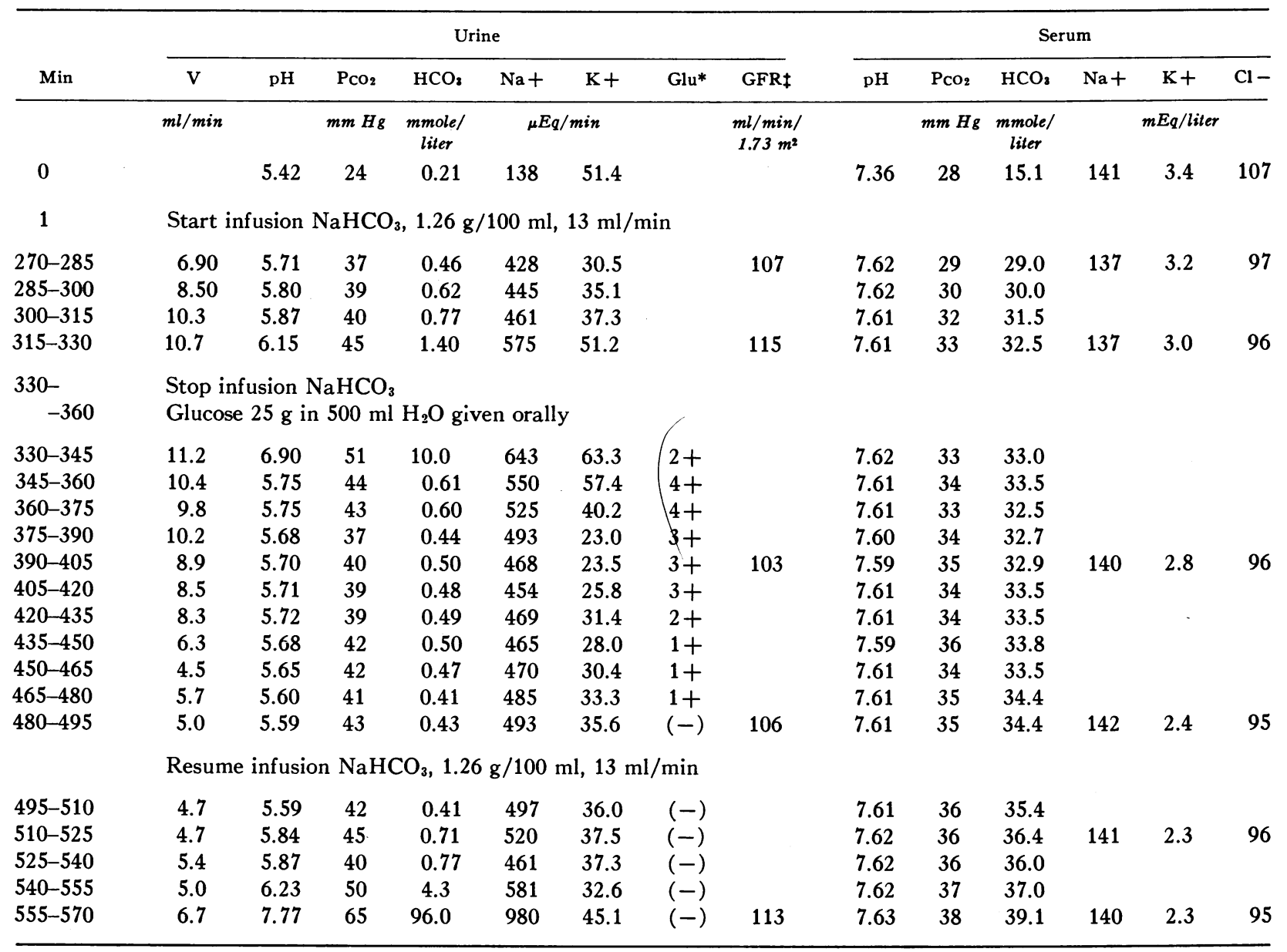

* Urinary glucose was determined by Dipstick (Ames Co. Elkhart, Ind.).

$\ddagger$ GFR was estimated by creatinine clearance.

than intake) occurred in all patients for up to 6 days, resulting in cumulative sodium deficits of $69-165 \mathrm{mEq}$ (mean 103.5 \pm 14.4 ). By the 7 th fasting day all subjects were in positive daily sodium balance and they retained sodium until about the 14th day. Thereafter, urinary sodium excretion approximated intake. No significant difference in sodium balance was noted between the subjects receiving $\mathrm{NaCl}$ and those given $\mathrm{NaHCO}_{3}$. This triphasic pattern for cumulative sodium balance is illustrated in Fig. 5. As a group, the greatest cumulative sodium deficit occurred on the 5 th fasting day, averaging $99.1 \pm 13.6 \mathrm{mEq}$. This deficit was then obliterated as sodium retention occurred. Mean cumulative balance was nil at the end of the 8th day and progressively positive until the 14 th day when it averaged $(+) 183.8$ $\pm 13.2 \mathrm{mEq}$ (range 165-222). Throughout the remainder of the fasting period external balance remained unchanged. The possibility that surreptitious food intake accounted for the observed sodium retention is excluded because it occurred in all patients at the same time, and because systemic acidosis and ketonuria continued unabated.

Chloride balance. There was a marked difference in the excretion of chloride in the patients receiving $\mathrm{NaCl}$ or $\mathrm{NaHCO}_{3}$. The former group, who received the same quantity of chloride before and during fasting, developed a chloruresis during the 1 st wk of starvation. During the phase of sodium retention urinary chloride excretion diminished. The subsequent period of neutral daily sodium balance was characterized by an essentially neutral daily chloride balance. In those subjects receiving $\mathrm{NaHCO}_{3}$, chloride excretion declined over the $1 \mathrm{st}$ wk of fasting to low levels. Chloride was then retained concurrently with sodium, and there was a simi- 


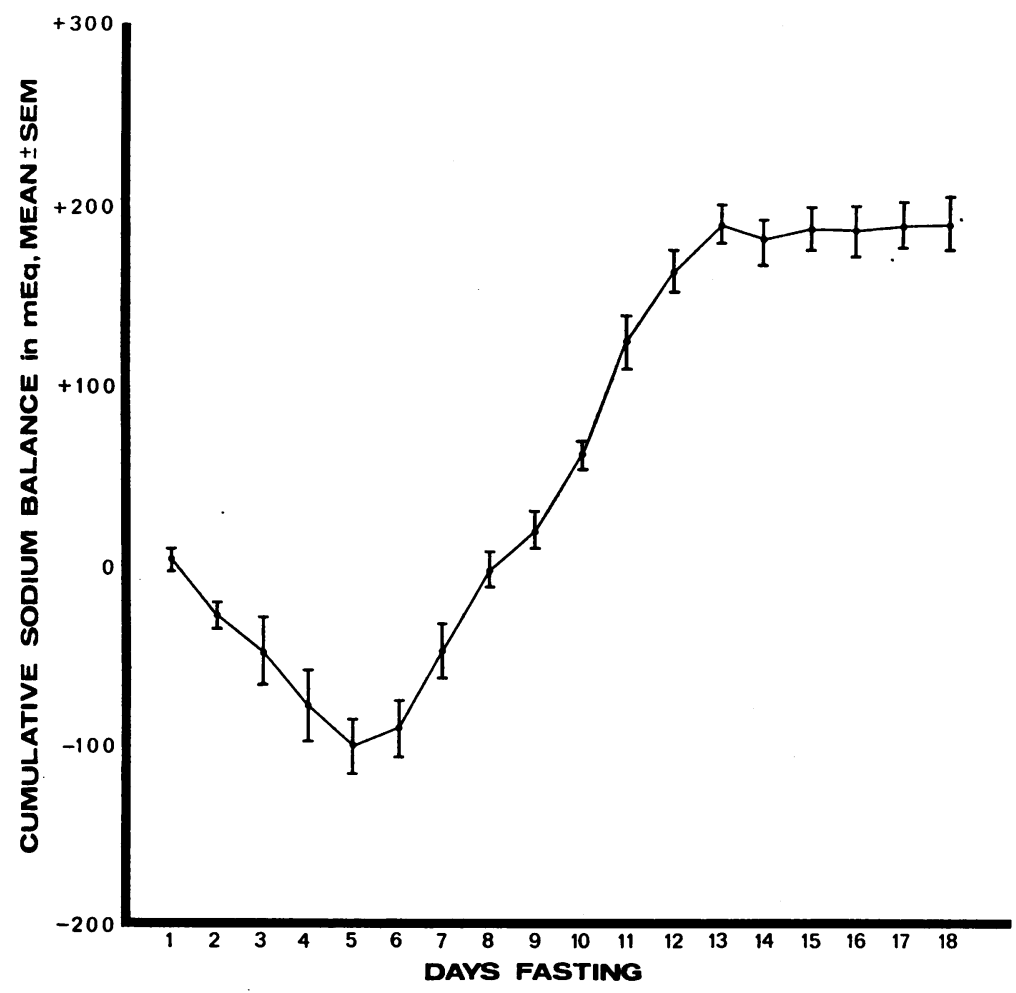

Figure 5 Cumulative sodium balance in seven subjects of the sodium balance study during 18 days of fasting with sodium supplements of 102 $(\mathrm{NaCl})$ or $160\left(\mathrm{NaHCO}_{3}\right) \mathrm{mEq} /$ day. The initial sodium deficit of fasting was followed by a period of reaccumulation of sodium culminating in a mean excess of about $180 \mathrm{mEq}$. "Escape" then occurred with no further change in cumulative sodium balance.

lar eventual appearance of neutral daily chloride balance. Positive cumulative chloride balance occurred in both groups. Fig. 6 depicts these results.

Potassium balance. The maneuver of abruptly increasing potassium intake from 40 to $60 \mathrm{mEq} /$ day at the inception of fasting diminished total body potassium deficits, principally by producing a positive balance in the first few days of fasting. Although a kaliuresis of fasting occurred, with mean potassium excretion rising from $45.2 \pm 6.7 \mathrm{mEq}$ on the 1 st day to $63.2 \pm 3.1$ on the 5 th day, daily balance was minimally negative. Cumulative potassium deficit was limited to less than $50 \mathrm{mEq}$ in all patients. As kaliuresis subsided, all patients came to positive cumulative potassium balance. These data are depicted in Fig. 7. Serum potassium remained between 3.8 and $4.5 \mathrm{mEq} / \mathrm{liter}$ throughout.

Serum values. Serum sodium remained unchanged from the prefast concentration throughout the period of observation. The mean serum bicarbonate concentration in subjects receiving $\mathrm{NaHCO}_{3}$ did not fall below $18.0 \mathrm{mEq} /$ liter (8th day) and thereafter rose gradually to 21.6 at the 18th day. In those receiving $\mathrm{NaCl}$, the lowest mean value of $14.5 \mathrm{mEq} /$ liter was reached on the 6th through 8th days, after which there was a gradual rise to 17.9 by the 18th day. The serum chloride concentration varied reciprocally. In subjects receiving $\mathrm{NaCl}$, this rose from a prefast mean of $104 \mathrm{mEq} /$ liter to 108 by the 3 rd day and remained at this level. In patients given $\mathrm{NaHCO}_{3}$, serum chloride fell from the same prefast mean to the range of $100-102$ by the 3 rd day, and this similarly persisted.

Weight loss. The mean total weight loss at the end of the sodium retaining phase (14th day) was $6.7 \pm 0.6$ $\mathrm{kg}$ this is significantly less weight loss $(P<0.001)$ than similar subjects studied by us who did not receive sodium supplements and averaged $9.5 \pm 0.4 \mathrm{~kg}$ weight loss at 14 days.

\section{DISCUSSION}

The observation of metabolic alkalosis when fasting patients resume food intake was first reported by Lennox in 1926 (1). More recently, Rapoport, From, and Husdan described metabolic alkalosis in three of four 
fasting subjects upon return to mixed diets (2). We studied this metabolic alteration in detail and have documented the regular occurrence of alkalosis when fasting was terminated by glucose feedings. The serum bicarbonate level in all subjects during refeeding was significantly higher than in the prefast period. While this study does not establish the duration of this alteration in acid-base balance, data obtained on other subjects after fasting who were ingesting a mixed diet at home indicate that some degree of metabolic alkalosis may persist for up to $2 \mathrm{wk}$. This is approximately the same duration as that of the postfast tendency for sodium retention.

The data indicate that several factors were responsible for the alkalosis of refeeding. These include: $(a)$ an increased renal bicarbonate reabsorptive capacity which occurs as a direct result of fasting, $(b)$ a further increment in this parameter subsequent to the ingestion of glucose, and (c) elevation of serum bicarbonate concentration to alkalotic levels by generation of "new" bicarbonate (metabolism of ketone bodies to bicarbonate, excretion of net acid. and additional mechanisms not detectable by balance methods). The major change in bicarbonate reabsorptive capacity occurred during fasting and before refeeding. Table $I$ indicates that $\mathrm{T}-\mathrm{HCO}_{3}$ was normal or slightly depressed during early fasting but then became elevated and remained above normal through the end of the $3 \mathrm{rd}$ wk. In the six subjects in which $\mathrm{Tm}$ was determined, the increased threshold was associated with a proportionate rise in $\mathrm{TmHCO}_{3}$. Fasting, therefore, causes no increase in the splay of the bicarbonate titration curve, and its effect on bicarbonate reabsorption is similar to that of elevated $\mathrm{Pco}_{2}$, potassium deficiency and chloride depletion (10-12).

Our data indicate that none of these factors were present in our patients. All developed the metabolic acidosis of starvation, with compensatory hypocapnia (Fig. 1). Although our subjects developed a kaliuresis of fasting, potassium supplements resulted in an external potassium balance which never became significantly negative (Fig. 7). Drenick, Blahd, Singer, and Lederer (13) have shown that intracellular potassium liberated by protein metabolism provides a significant quantity of potassium during starvation, so that after the 3rd wk of fasting total potassium balance is neutral in subjects not receiving potassium supplements. The total potassium balance in our subjects was therefore probably much more positive than our calculations indicate. Our estimation of the external sodium balance is supported by chloride balance data (Fig. 6) and the diminished weight loss observed in these patients. Sodium balance averaged (+) $180 \mathrm{mEq}$ at the end of the 14th fasting day, and subtraction for as-

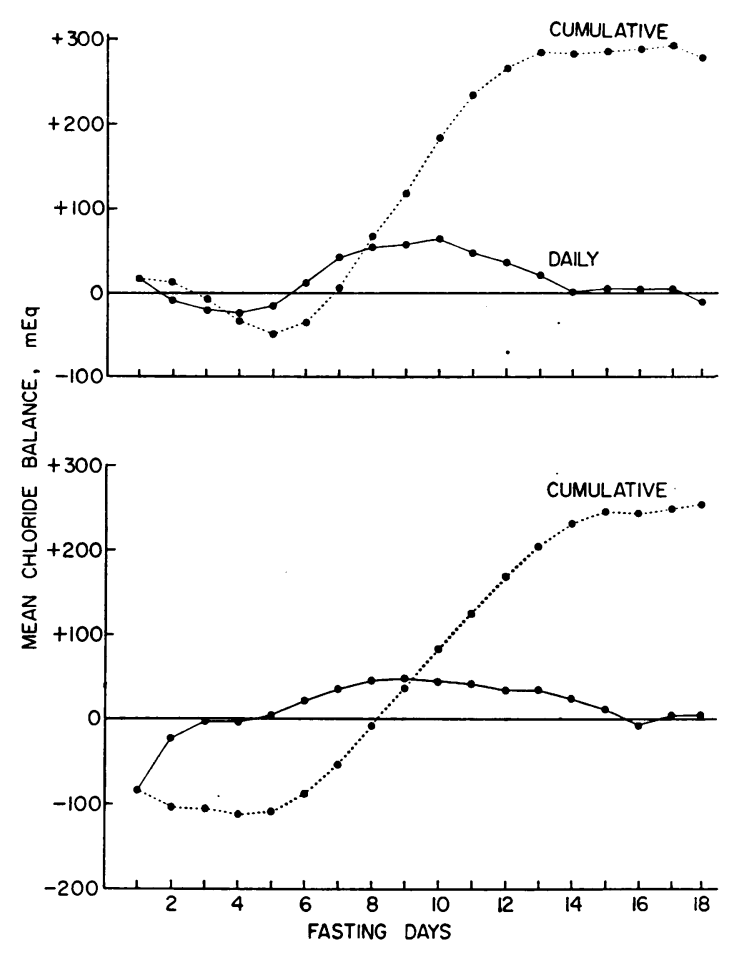

Figure 6 Daily (black line) and cumulative (dotted line) chloride balance during 18 days fasting with supplementation of sodium chloride (upper figure) or sodium bicarbonate (lower). After an initial chloruresis, there was a period of chloride retention during which chloride balance became progressively positive, and followed by essentially neutral daily chloride balance. In general, the pattern of renal chloride excretion approximated that of urinary sodium excretion.

sumed extrarenal loss of as much as $5 \mathrm{mEq} /$ day would still yield a positive sodium balance in excess of 100 $\mathrm{mEq}$. Therefore, a negative external sodium balance sufficient to explain an elevated bicarbonate threshold was unlikely to have been present. Our data are compatible with the results of Maag $\varnothing$ e, who reported that sodium supplementation prevented starvation-induced decreases of blood volume (14). Furthermore, our conclusion that the increase in bicarbonate reabsorptive capacity is not due to deficits of sodium chloride or potassium is supported by the observations of a normal bicarbonate threshold during early fasting when negative balances of these substances were maximal, and of an increased bicarbonate reabsorption during later phases of fasting when these deficits were being repaired (Table I).

The administration of glucose, both acutely and over prolonged periods (refeeding study), was followed by a further increase in the elevated bicarbonate reabsorptive capacity due to fasting per se. The ingestion of $25 \mathrm{~g}$ of glucose rapidly augmented $\mathrm{T}-\mathrm{HCO}_{3}$ by 


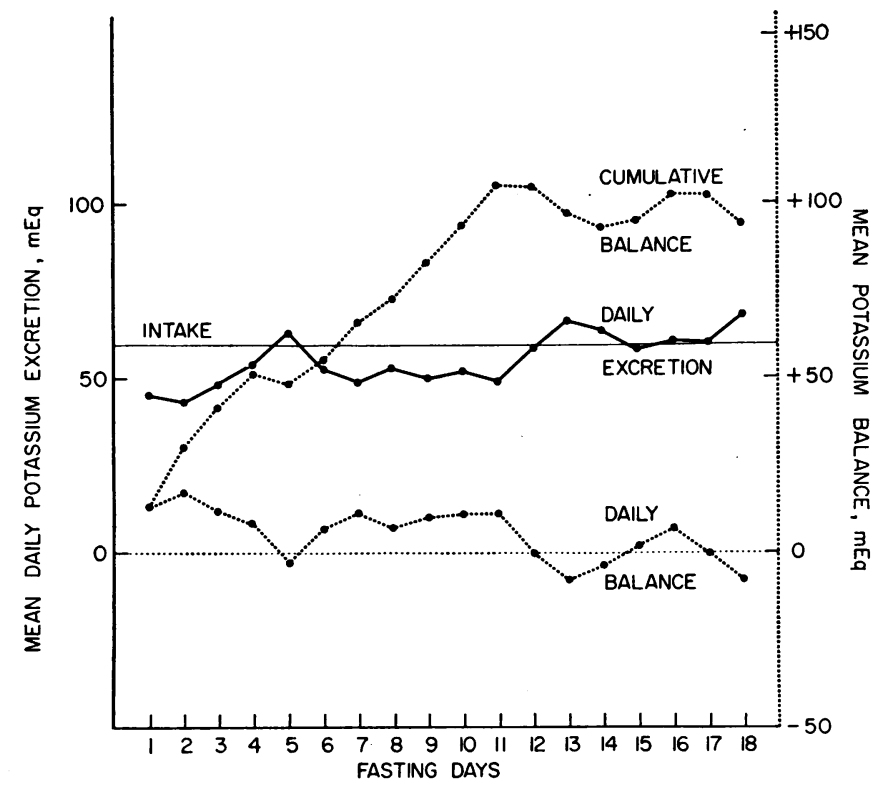

FIGURE 7 Mean daily potassium excretion (black line) and daily and cumulative potassium balance (dotted line) during 18 days of fasting while receiving potassium supplements of 60 $\mathrm{mEq} /$ day. Increasing potassium intake from 40 to $60 \mathrm{mEq} /$ day at the inception of fasting effectively minimized potassium deficits during starvation and all subjects developed a positive cumulative potassium balance.

about $3 \mathrm{mmoles} /$ liter. During refeeding, the serum bicarbonate concentration of the subjects receiving $\mathrm{NaCl}$ rose above their prefast levels but did not reach their new $\mathrm{T}-\mathrm{HCO}_{3}$ since urinary $\mathrm{pH}$ remained low throughout this period (Figs. 1,2). However, since under conditions of unimpaired ability to excrete acid, the serum bicarbonate concentration is quite close to $\mathrm{T}-\mathrm{HCO}_{3}$, it is probable that the threshold in these patients was very close to the serum bicarbonate concentration. Of the subjects receiving $\mathrm{NaCHO}_{3}$, one retained all of the ingested dose of the first 2 days of refeeding while serum bicarbonate rose to $33.1 \mathrm{mmoles} / \mathrm{liter}$, at which point she began to excrete part of her daily bicarbonate intake. The other patient receiving $\mathrm{NaHCO}_{3}$ retained a large part of the administered bicarbonate on the first refeeding day while serum bicarbonate concentration rose to $30.2 \mathrm{mmoles} / \mathrm{liter}$. Thereafter she excreted most of the ingested bicarbonate and maintained her serum bicarbonate concentration near this level. From these observations we conclude that the $\mathrm{T}-\mathrm{HCO}_{s}$ of these latter subjects was about 33 and 30 mmoles/liter, respectively.

The data presented in Table I suggest a relationship between bicarbonate reabsorptive capacity and the status of renal sodium reabsorption. Highest values of $\mathrm{T}-\mathrm{HCO}_{3}$ were observed during the 2 nd wk of fasting, when there was avid sodium retention. Slatopolsky, Hoffsten, Purkerson, and Bricker (15) and Kurtzman (16) have proposed that a $\mathrm{Tm}$ for bicarbonate normally does not exist and is a measurement artifact introduced by the volume expansion necessary to raise the serum bicarbonate concentration. Kurtzman (16) has shown that volume expansion depresses bicarbonate reabsorption, and both Slatopolsky et al. and Kurtzman (16) have presented evidence that when volume expansion is prevented or when subjects are avidly retaining sodium, no $\mathrm{Tm}$ for bicarbonate is demonstrable. These observations suggest that bicarbonate reabsorption is in large part a function of renal sodium handling: i.e., that volume expansion inhibits bicarbonate reabsorption by depressing sodium reabsorption, and that volume contraction by augmenting sodium conservation increases bicarbonate reabsorption. This interpretation is supported by our results over the first 2 wk of fasting which demonstrate that bicarbonate reabsorption is normal or slightly depressed during the salt-losing phase but is elevated during the sodium conserving phase (Table I). Further, the augmentation in bicarbonate reabsorption during refeeding with glucose is accompanied by a simultaneous increase in sodium reabsorption (Fig. 3). Thus, the mechanism by which glucose promotes sodium retention during fasting 
may also be responsible for the increase in bicarbonate reabsorptive capacity during refeeding.

The fact that bicarbonate reabsorption remained elevated after daily sodium balance was reestablished is difficult to reconcile with the hypothesis that changes in bicarbonate reabsorption were secondary to alterations in sodium reabsorption. However, an explanation may be derived from the concept that a determinant of bicarbonate reabsorptive capacity is the portion of the nephron where reabsorption takes place. Cohen, Chazan, and Garella, on the basis of clearance studies, have suggested that bicarbonate is preferentially reabsorbed in the proximal tubule and chloride in the distal nephron (17). This concept is supported by the micropuncture experiments of Malnic, Mello Aires, and Lacaz Vieira suggesting preferential reabsorption of bicarbonate in the proximal tubule (18), and by the clearance studies of Rosin, Katz, Rector, and Seldin indicating that chloride is more reabsorbable than bicarbonate in the ascending limb (19). It seems to follow that any condition which increases fractional reabsorption in the proximal tubule would also increase bicarbonate reabsorption, and maneuvers which depress proximal reabsorption would diminish bicarbonate reabsorptive capacity. Certainly there is abundant evidence that reabsorption in the proximal tubule is depressed by volume expansion and increased by volume contraction (e.g., constriction of the thoracic inferior vena cava). Thus, the decrease in bicarbonate reabsorptive capacity observed by Kurtzman (16) during volume expansion might be the result of depressed proximal tubular reabsorption. Similarly, the blunting of the effect of volume expansion on bicarbonate reabsorption by constriction of the thoracic inferior vena cava (16) could be attributed to the enhancement of proximal tubular reabsorption due to this maneuver. It might similarly be argued that the method employed by Slatopolsky et al. (15) of "minimizing extracellular volume expansion" during bicarbonate titration studies by pretreatment with low salt diets and diuretics had produced a state of volume depletion and enhanced proximal tubular reabsorption, thereby increasing bicarbonate reabsorptive capacity. The proposal of Cohen et al. (17) that the site of the nephron where the reabsorption of filtrate takes place is a controlling factor in bicarbonate reabsorption does not preclude the acceptance of the hypothesis of Slatopolsky et al. (15) and Kurtzman (16) that the sodium retaining state of the organism is a major determinant of the bicarbonate reabsorptive capacity. As conditions which cause sodium retention generally augment, and those which increase sodium excretion generally depress reabsorption in the proximal tubule, the two ideas merge quite well.
If we accept the hypothesis that bicarbonate reabsorptive capacity is in large part a function of fractional reabsorption in the proximal tubule, a possible explanation of our results can be constructed. We have previously shown that proximal tubular reabsorption of filtrate is decreased during the early "natriuretic phase" of fasting and that glucose administration at this time increases reabsorption in the proximal tubule $(20)$. This would explain both the decreased bicarbonate reabsorption observed during this early period and the increased reabsorption after glucose. It seems possible that proximal tubular reabsorption increases during the period of avid sodium retention and thereby accounts for the increased bicarbonate reabsorptive capacity during this phase. To explain the observation that bicarbonate reabsorption remains elevated after daily sodium balance becomes neutral, we propose that proximal tubular reabsorption remains increased but that sodium balance is reestablished by a greater rejection of sodium at distal tubular sites. This proposal is in accord with evidence from both micropuncture and balance studies which suggest that proximal and distal tubular sodium reabsorption may be dissociated according to the needs of the organism (21-24).

Neither our studies nor those of Rapoport et al. (2) indicate the origin of the "new" bicarbonate responsible for the alkalosis. Increases in bicarbonate reabsorptive capacity permit a metabolic alkalosis by reclamation of a greater portion of the filtered bicarbonate, but do not cause the serum bicarbonate to rise. Metabolism of the B-OH-butyrate and acetoacetate composing the "anion gap" to bicarbonate would return serum bicarbonate concentration to prefast values only (25). An increase in bicarbonate concentration above the prefast value to alkalotic levels implies either the generation of "new" bicarbonate or a contraction of the bicarbonate space. As there were marked sodium retention, weight gain, and edema during refeeding it seems probable that the extracellular volume was increased, and a decrease in the bicarbonate space, while impossible to exclude, is unlikely. The quantity of net acid excreted by the subjects receiving $\mathrm{NaCl}$ was inadequate to explain the rise in serum bicarbonate concentration, even if we make the unlikely assumptions that endogenous acid production decreased to zero, that the bicarbonate was distributed only in the extracellular fluid, and that the extracellular fluid volume did not increase. A similar conclusion was reached by Rapoport et al. (2), who postulated that hydrogen ions shifted into cells during refeeding, displacing potassium and resulting in an intracellular acidosis and the development of an extracellular alkalosis. Our studies offer no insight into the mechanism involved in the elevation of the serum bicarbonate, but we should point out that the inability of external balance 
studies to explain the elevated bicarbonate values in metabolic alkalosis is well known (26) and not confined to the refeeding of fasting subjects. Whether the discrepancy is due to the inherent inaccuracy of balance methods or to undetectable electrolyte shifts within the organism remains to be determined.

\section{ACKNOWLEDGMENTS}

This study was supported by research grants from the U. S. Army Research and Development Command, the National Science Foundation, and the Kelsey-Leary Foundation of Houston, Tex.

\section{REFERENCES}

1. Lennox, W. G. 1926. Chemical changes in the blood during fasting in the human subject. Arch. Int. Med. 5: 553.

2. Rapoport, A., G. L. A. From, and H. Husdan. 1965. Metabolic studies in prolonged fasting. I. Inorganic metabolism and kidney function. Metab. (Clin. Exp.). $14: 31$.

3. Sigman, E. M., C. M. Elwood, and F. Knox. 1966. The measurement of glomerular filtration rate in man with sodium iothalamate ${ }^{181} \mathrm{I}$ (Conray). J. Nucl. $\mathrm{Med}$. 7: 60 .

4. Hastings, A. B., and J. Sendroy, Jr. 1925. The effect of variation in ionic strength on the apparent first and second dissociation constants of carbonic acid. J. Biol. Chem. 65: 445.

5. Rodriguez Soriano, J., H. Boichis, and C. H. Edelmann. 1967. Bicarbonate reabsorption and hydrogen ion excretion in children with renal tubular acidosis. $J$. Pediat. 71: 802 .

6. Haag, B. L., M. M. Reidenberg, C. R. Schuman; and B. J. Channick. 1967. Aldosterone, 17-hydroxycorticosteroid, 17-ketosteroid, and fluid and electrolyte responses to starvation and selective refeeding. Amer. J. Med. Sci. $254: 652$.

7. Benedict, F. G. A study of prolonged fasting. 1915 Carnegie Institution of Washington Publication No. 203. Washington, D. C.

8. Conway, E. J. 1957. In Microdiffusion Analysis and Volumetric Error. Crosby Lockwood \& Sons Ltd., London. 4th edition. 98.

9. Snedecor, G. W. 1956. Statistical Methods Applied to Experiments in Agriculture and Biology. 5th edition. Iowa State University Press, Ames, Iowa.

10. Rector, F. C., Jr., D. W. Seldin, A. A. Roberts, and J. S. Smith. 1960. The role of plasma $\mathrm{CO}_{2}$ tension and carbonic anhydrase activity in the renal reabsorption of bicarbonate. J. Clin. Invest. 39: 1706.

11. Garella, S., J. A. Chazan, and J. J. Cohen. 1970. Saline resistant metabolic alkalosis or "chloride wasting nephropathy." Report of four patients with severe potassium depletion. Ann. Int. Med. 73: 31 .
12. Kassirer, J. P., and W. B. Schwartz. 1966. The response of normal man to selective depletion of hydrochloric acid. Amer. J. Med. 40: 10.

13. Drenick, E. J., W. H. Blahd, F. R. Singer, and M. Lederer. 1966. Body potassium content in obese subjects and potassium depletion during prolonged fasting. Metab. (Clin. Exp.). 18: 278.

14. Maag $\varnothing \mathrm{e}, \mathrm{H} .1968$. Changes in blood volume during absolute fasting with and without sodium chloride administration. Metab. (Clin. Exp.). 17: 133.

15. Slatopolsky, E., P. Hoffsten, M. Purkerson, and N. S. Bricker. 1970. On the influence of extracellular fluid volume expansion and of uremia on bicarbonate reabsorption in man. J. Clin. Invest. 49: 988.

16. Kurtzman, N. A. 1970. Regulation of renal bicarbonate reabsorption by extracellular volume. J. Clin. Invest. 49: 586.

17. Cohen, J. J., J. A. Chazan, and S. Garella. 1970. The interrelationship between ECF volume and ECF anion composition in the regulation of sodium excretion. Clin. Sci. 39: 475.

18. Malnic, G., M. Mello Aires, and F. Lacaz Vieira. 1970. Chloride excretion in nephrons of rat kidney during alterations of acid-base equilibrium. Amer. J. Physiol. 218: 20 .

19. Rosin, J. M., M. A. Katz, F. C. Rector, Jr., and D. W. Seldin. 1970. Acetazolamide in studying sodium reabsorption in diluting segment. Amer. J. Physiol. 219: 1731.

20. Schloeder, F. X., and B. J. Stinebaugh. 1970. Renal tubular sites of natriuresis of fasting and glucose-induced sodium conservation. Metab. (Clin. Exp.). 19: 1119.

21. Higgins, B. A., J. R. Nassim, J. Collins, and A. Hilb. 1964. The effect of bendrofluazide on urine calcium excretion. Clin. Sci. $27: 457$.

22. Suki, W. N., R. S. Schwettmann, F. C. Rector, Jr., and D. W. Seldin. 1968. Effect of chronic mineralocorticoid administration on calcium excretion in the rat. Amer. $J$. Physiol. 215 : 71.

23. Howards, S. S., B. B. Davis, F. G. Knox, F. S. Wright, and R. W. Berliner. 1968. Depression of fractional sodium reabsorption by the proximal tubule of the dog without sodium diuresis. J. Clin. Invest. 47: 1561.

24. Davis, B. B., M. J. Walter, and H. V. Murdaugh, Jr. 1969. Renal response to grade saline challenge. Amer. J. Physiol. 217: 1604.

25. Cahill, G. F., Jr., M. G. Herrera, A. P. Morgan, J. S. Soeldner, J. Steinke, P. L. Levy, G. A. Reichard, Jr., and D. M. Kipnis. 1966. Hormone-fuel interrelationships during fasting. J. Clin. Invest. 45: 1751.

26. Gulyassy, P. F., C. van Ypersele de Strihou, and W. B. Schwartz. 1962. On the mechanism of nitrate-induced alkalosis. The possible role of selective chloride depletion in acid-base regulations. J. Clin. Invest. 41: 1850. 